\title{
Modelling fermentative hydrogen production of cheese wastewater
}

\author{
T. Ravanini do Nascimento*, W. Cavalcante, V.M.C. Blanco,
} G.H.D. Oliveira, M. Zaiat, R. Ribeiro

*thiago.ravanini@gmail.com

University of São Paulo, Brazil

\section{HIGHLIGHTS:}

- Bio-hydrogen recovery during secondary fermentation

- Lactate plays a fundamental role in carboxylic chain elongation

- Modified ADM1 simulated the syntrophism between species

BACKGROUND: Brazilian agroindustry has an expressive, but not exploited, source of energy in its wastewaters and by-products. For instance, cheese whey (CW) disposed from the dairy industry represents a high residual sugar-content (lactose) with potential to energy recovery by anaerobic bioprocess ${ }^{1,2}$. In anaerobic microbiomes, sugar and other substrates are commonly hydrolyzed and fermented to short-chain monocarboxylic acids (SCCAs), such as: acetic, propionic and butyric acids. In turn, the reverse $\beta$-oxidation pathway might transform SCCAs into mediumchain monocarboxylic acids, also known as chain elongation process (CE).

Despite organic acid outputs, both processes are well established as high biological hydrogen (bio- $\mathrm{H}_{2}$ ) yielders. Also they are affected by carbonsource, key electron donors, partial hydrogen pressure $\left(\mathrm{P}_{\mathrm{H} 2}\right)$, $\mathrm{pH}$, reactor microbiomes and temperature conditions ${ }^{3,4}$. Additionally, the feasibility of electron donor source implies on CE-capable microorganisms activity, which can recover $\mathrm{H}_{2}$ through SCCA consumption ${ }^{5}$. Conversely, $\mathrm{P}_{\mathrm{H} 2}$ can determine both fermentative and CE pathways, acting as thermodynamic inhibitor ${ }^{6}$. In addition, $\mathrm{pH}$ can also act as inhibitor in both processes, leading to electron control via disruption of bio- $\mathrm{H}_{2}$ production pathways ${ }^{7}$.

Mathematical modelling is a powerful tool to better understand complex interactions amongst microbiomes and inhibition factors, as presented so far. Thus, the aim of the present study is to develop a mathematical model to depict microbiome interaction between dark fermentative and CE biomasses. Experimental data to calibrate the model was gathered on a previous study of dark fermentative bio- $\mathrm{H}_{2}$ production, in which batch essays of synthetic cheese whey wastewater were inoculated with continuous flow experiment biomass ${ }^{8}$. In order to consider chain elongation biomass $\left(\mathrm{X}_{\mathrm{CE}}\right)$, kinetics and balances, along with $\mathrm{P}_{\mathrm{H} 2}$ and $\mathrm{pH}$ effects, a modified version of Anaerobic Digestion Model n.1 (ADM1) ${ }^{9}$ is proposed.

RESULTS \& DISCUSSION: The model was successfully implemented in MatLabß. In order to evaluate different microbial communities, biomass was split onto dark fermenters ( $\left.\mathrm{X}_{\mathrm{SU}}\right)$ and $\mathrm{X}_{\mathrm{CE}}$. Latter was considered to grow 
during lactose fermentation and $\mathrm{CE}^{10}$. To avoid early $\mathrm{CE}$ synthesis (i.e. bio$\mathrm{H}_{2}$ and $n$-butyrate), $\mathrm{X}_{\text {ce }}$ was inhibited by a competitive lactate function. Which implied on four new parameters to be estimated (Table 1 ).

Table 1. Petersen matrix of proposed model, estimated parameters in bold.

\begin{tabular}{|c|c|c|c|c|c|c|c|c|}
\hline Comp. $\rightarrow$ & $\mathrm{S}_{\mathrm{su}}$ & $\mathrm{S}_{\mathrm{bu}}$ & $\mathrm{S}_{a c}$ & $\mathrm{~S}_{l a c}$ & $\mathrm{~S}_{\mathrm{H}_{2}}$ & $X_{\mathrm{su}}$ & $X_{\mathrm{CE}}$ & Rate \\
\hline Uptake of sugar & -1 & & $f_{a c, s u}$ & $\mathrm{f}_{\mathrm{lac}, \mathrm{su}}$ & $f_{h 2, s u}$ & $Y_{\text {su }}$ & $\mathrm{Y}_{C E}$ & $\mathrm{k}_{\mathrm{m}, \mathrm{su}} \frac{\mathrm{S}_{\mathrm{su}}}{\mathrm{K}_{\mathrm{s}, \mathrm{su}}+\mathrm{S}_{\mathrm{su}}} \mathbf{X}_{\text {su }} \mathrm{I}_{\mathrm{pH}}$ \\
\hline & & & & & & & & $\mathbf{k}_{\mathbf{m}, \mathbf{l a c}} \frac{\mathrm{J}_{\mathrm{su}}}{\mathbf{K}_{\mathbf{s}, \text { lac }}+\mathrm{S}_{\mathrm{lac}}} \mathbf{X}_{\mathbf{C E}} \mathrm{I}_{\mathrm{pH}}$ \\
\hline $\begin{array}{l}\text { Uptake of } \\
\text { butyrate }\end{array}$ & & -1 & & & & & & \\
\hline Uptake of acetate & & & -1 & & & & $\mathrm{Y}_{C E}$ & \\
\hline Uptake of lactate & & $f_{\text {bu,lac }}$ & $\mathrm{f}_{\mathrm{ac}, \mathrm{lac}}$ & -1 & $\mathrm{f}_{\mathrm{h} 2, \mathrm{lac}}$ & & & $\mathbf{k}_{\mathbf{m}, \mathrm{CE}} \frac{\mathrm{S}_{\mathrm{lac}}}{\mathrm{K}_{\mathrm{s}, \mathrm{CE}}+\mathrm{S}_{\mathrm{lac}}} \mathrm{X}_{\mathrm{CE}} \mathrm{I}_{\mathrm{pH}} \mathrm{I}_{\mathrm{H}_{2}} \mathrm{I}_{\mathrm{lac}}$ \\
\hline Uptake of $\mathrm{H}_{2}$ & & & & & -1 & & & \\
\hline $\mathrm{X}_{\text {su }}$ decay & & & & & & -1 & & $\mathrm{k}_{\mathrm{dec}} \mathrm{X}_{\mathrm{su}}$ \\
\hline $\mathrm{X}_{\mathrm{CE}}$ decay & & & & & & & -1 & $\mathrm{k}_{\mathrm{dec}} \mathrm{X}_{\mathrm{CE}}$ \\
\hline
\end{tabular}

Due to reduced number of data between 75 to $150 \mathrm{~h}$, a $\beta$-spline interpolation was used to better fit data. The initial $X_{C E} / X_{S U}$ was kept constant on 0.167. Biomasses yields, sugar consumption kinetics and CE half saturation constants were based on literature ${ }^{8,11}$ and other parameters were adopted from ADM1 framework.

Time dependent simulation profiles indicated good agreement with data (Figure 1 ), with a slight early bio- $\mathrm{H}_{2}$ production and diverging pattern on $n$ butyrate production around 150 Parameters were estimated by minimizing the sum of the absolute values of the deviations, presenting the following values: carbohydrates 0.88 , acetate $0.16, n$-butyrate 0.56 , lactate $0.45, \mathrm{H}_{2}$ gas 0.04 , biomass (not plotted) 0.27 and 0.16 for $\mathrm{pH}$.

Figure 1. Experimental data (scatters) compared to simulation data (lines) obtained by modified ADM1 structure. A chart represents sugar and SCCAs dynamics, and $\mathbf{B}$, accumulated $\mathrm{H}_{2}$ production and $\mathrm{pH}$ variation patterns.
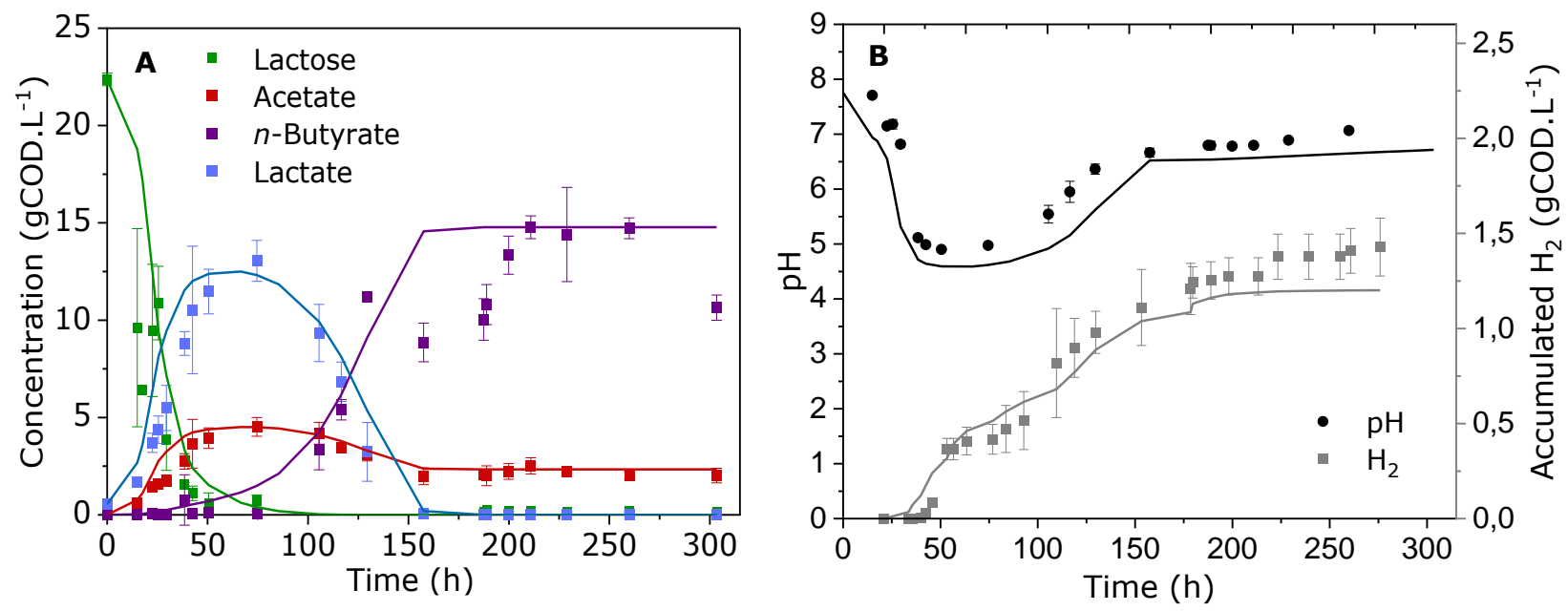

CONCLUSION: The developed ADM1 model for acetate and lactate CEcoupled, considering syntrophism between two biomasses, could represent both bio- $\mathrm{H}_{2}(\%)$ and $n$-butyrate production. 


\section{REFERENCES}

1. Chandra, R., Castillo-Zacarias, C., Delgado, P. \& Parra-Saldívar, R. A biorefinery approach for dairy wastewater treatment and product recovery towards establishing a biorefinery complexity index. $J$. Clean. Prod. 183, 1184-1196.

2. Prazeres, A. R., Carvalho, F. \& Rivas, J. Cheese whey management: A review. J. Environ. Manage. 110, 48-68.

3. Carvalho, F., Prazeres, A. R. \& Rivas, J. Science of the Total Environment Cheese whey wastewater: Characterization and treatment. Sci. Total Environ. 445-446, 385-396.

4. Spirito, C. M., Richter, H., Rabaey, K., Stams, A. J. M. \& Angenent, L. $\mathrm{T}$. Chain elongation in anaerobic reactor microbiomes to recover resources from waste. Curr. Opin. Biotechnol. 27, 115-122.

5. Angenent, L. T. et al. Chain elongation with reactor microbiomes: open-culture biotechnology to produce biochemicals. Environ. Sci. Technol. 50, 34.

6. Atasoy, M., Eyice, O. \& Cetecioglu, Z. A comprehensive study of volatile fatty acids production from batch reactor to anaerobic sequencing batch reactor by using cheese processing wastewater. Bioresour. Technol. 311, 123529.

7. de Sousa e Silva, A., Morais, N. W. S., Coelho, M. M. H., Pereira, E. L. \& dos Santos, A. B. Potentialities of biotechnological recovery of methane, hydrogen and carboxylic acids from agro-industrial wastewaters. Bioresour. Technol. Reports 100406.

8. Blanco, V. M. C., Oliveira, G. H. D. \& Zaiat, M. Dark fermentative biohydrogen production from synthetic cheese whey in an anaerobic structured-bed reactor: Performance evaluation and kinetic modeling. Renew. Energy 139, 1310-1319.

9. Batstone, D. J. et al. The IWA Anaerobic Digestion Model No 1 (ADM1). Water Sci. Technol. 45, 65-73.

10. Diez-Gonzalez, F., Russell, J. B. \& Hunter, J. B. The role of an NADindependent lactate dehydrogenase and acetate in the utilization of lactate by Clostridium acetobutylicum strain P262. Arch. Microbiol. 164, 36-42.

11. Satpathy, P., Biernacki, P., Uhlenhut, F., Cypionka, H. \& Steinigeweg, S. Modelling anaerobic digestion in a biogas reactor: ADM1 model development with lactate as an intermediate (Part I). J. Environ. Sci. Heal. - Part A Toxic/Hazardous Subst. Environ. Eng. 51, 1216-1225. 